\title{
The impact of sitting time and physical activity on mental health during COVID-19 lockdown
}

\author{
Matthew Pears ${ }^{1}$. Susanna Kola-Palmer ${ }^{1} \cdot$ Liane Beretta De Azevedo $^{2}$
}

Received: 29 November 2020 / Accepted: 28 May 2021 / Published online: 10 June 2021

(c) Crown 2021

\begin{abstract}
Objective The primary aim of this study was to investigate the association between physical activity (PA) and sitting time on adults' mental health (i.e., depression, anxiety and wellbeing) and the influence of mediators and confounders.

Methods An online survey was disseminated in the UK between May and June 2020. A total of 284 participants (33.5 \pm 12.4 years) self-reported their PA, sitting time and mental health through validated questionnaires.

Results Multiple stepwise regression analysis revealed that being of younger age, female, on a lower income, with one or more comorbid health conditions, with a previous diagnosis of mood disorder and increased sitting time independently correlated with higher depression scores $(F(13,219)=12.31, p<0.001)$, and explained $42 \%$ of the variance. Similar results were found for wellbeing where socio-demographic, health outcomes and sitting time influenced the subjective wellbeing $(F$ $(14,218)=5.77, p<0.001,27 \%$ variance $)$, although only socio-demographic and health outcomes contributed to the variation in anxiety score $(F(13,219)=7.84, p<0.001,32 \%$ variance). PA did not explain variation when sitting time was taken into account in any of the models. Combined analysis revealed that participants with lower sedentary time $(<8 \mathrm{~h})$ and with both low or moderate and high PA presented a significantly lower depression score [low PA: $(B=-2.7,95 \%$ CI $-4.88,-0.52)$; moderate and high PA $(B=-2.7,-4.88,-0.52)]$.

Conclusion Sitting time was strongly associated with adverse mental health during COVID-19 lockdown and should be considered in future public health recommendations.
\end{abstract}

Keywords Pandemic $\cdot$ Depression $\cdot$ Anxiety $\cdot$ Wellbeing $\cdot$ Sedentary behaviour $\cdot$ Regression

\section{Introduction}

Since the end of 2019, a life-threatening strain of the severe acute respiratory syndrome coronavirus (COVID-19) has caused extreme global public health concern. The personto-person transmission of the infection led global governments to deploy policies of isolation and social distancing to control the pandemic [1,2]. This caused a spike in cases of stress disorders [3], depression, anxiety [4, 5], and behavioural changes towards harmful health consequences in countries where COVID-19 lockdown was in place [6,

Liane Beretta De Azevedo

1.azevedo@hud.ac.uk

1 Department of Psychology, University of Huddersfield, Huddersfield HD1 3DH, West Yorkshire, UK

2 Department of Allied Health Professionals, Sports, and Exercise, University of Huddersfield, Queensgate, Huddersfield HD1 3DH, West Yorkshire, UK
7]. Currently, depression is the leading cause of disability around the world, affecting approximately 264 million people [8]. Anxiety is also one of the most prevalent psychiatric disorder with reports that one-third of the population may suffer from anxiety during their lifetime [9]. Social isolation, distancing, and loneliness have significant implications for psychological symptoms including depression, anxiety, and reduction in their quality of life [10-12]. This can increase cardiovascular risk and all-cause mortality [13, 14]. Furthermore, increased anxiety and depressive cognitions can dysregulate the immune and endocrine systems and compromises body immunity $[15,16]$. These effects hinder the ability to combat COVID-19, as the disease can further suppress the immune system responses [17]. Indeed, a recent study highlighted that people with suspected COVID-19 symptoms had higher depression likelihood and lower healthrelated quality of life [18].

There has been strong evidence that physical activity is an effective strategy in reducing anxiety, depression, and 
negative mood [19-21], which has been confirmed by systematic reviews of prospective studies [22] and randomised controlled trials [23]. The multiple benefits of physical activity for physical and mental wellbeing was recognised by the UK government, when the first guidance of the lockdown was published [24], which included exercising outdoors as one of the few reasons why people could leave home [25]. However, evidence of physical activity behaviour and the effect on mental health during lockdown has only started to be explored by the literature. The recent literature consistently showed a decrease in physical activity and an increase in sitting time [26] with an effect on wellbeing [27]. A survey from Australia reported that changes in physical activity were associated with higher depression, anxiety, and stress symptoms during the lockdown period [22, 28]. Meanwhile, studies from America reported that participants who reduced physical activity and increased screen time from pre and post COVID-19 increased the chances of depression loneliness and stress [29], while another reported a positive effect of light activity on mental health outcomes [30]. Finally, a recent UK online survey reported that mental health outcomes (depression, anxiety, and mental wellbeing) were negatively associated with moderate to vigorous physical activity per day [31].

Until now, most of the studies have focused on physical activity instead of sedentary behaviour, and there is evidence that imposing sedentary behaviour has a negative impact on mental wellbeing even in a short time period of 7 days [32]. However, it has not yet known if physical activity could mediate the adverse effects of sedentary behaviour on mental health during lockdown restriction. Similarly, there is a need for further understanding of the impact of cofounders, such as socioeconomic status and other pre-existing health conditions which were already seen as predictors of poorer mental health during the lockdown [31].

Therefore, the primary aim of the study was to investigate the independent and combined effects of physical activity and sitting time on adults' mental health with a particular focus on depression, anxiety, and mental wellbeing during the UK lockdown restrictions, including the analysis of potential mediators and confounders of this association.

\section{Methods}

\section{Study design}

This is a cross-sectional study which utilised an online survey to investigate activity behaviour and mental health status. The study followed guidance from the Strengthening the Reporting of Observational Studies in Epidemiology (STROBE) guidelines [33]. The study received ethical approval from the School of Human \& Health Sciences at the University of Huddersfield (application number
SREIC/2020/051). Participants were informed at the beginning of the survey that participation was voluntary and provided with further information about the study. Informed consent was implied by completing the questionnaire. Participants who complete the survey were entered into a prize draw of 30 prizes of $£ 50$ Amazon vouchers.

\section{Participants and setting}

We recruited a convenience sample via University staff and student e-mailing list along with University social media advertisements performed by their representatives. In addition, previously identified gatekeepers in Local Authority and Public Health England were asked to support and promote the study through their network, organisation websites, and social media. Inclusion criteria were participants age 18 or over and UK residents.

Data were collected during the COVID-19 lockdown in the UK from May to June 2020. During this period, the UK was primarily in Phase 1 of the lockdown in which people were advised to stay at home and just leave the house for shopping for basic necessities, one form of exercise a day, any medical need or to provide care to help a vulnerable person or travelling to and from work if you cannot work from home. However, from 1st of June, the UK moved to Phase 2 in which people from different households were allowed to meet in groups of six, in gardens and outdoor spaces. Figure 1 report the CONSORT diagram of participants.

\section{Measurements}

An online survey was created using Qualtrics XM survey platform [34] and disseminated online. The survey collected (1) demographic and pre-existing health conditions; (2) habitual physical activity, and (3) mental Health. The demographic data included age, gender, ethnicity, education, socio-economic status, children living in the home, outdoor space, and previous health conditions.

\section{Physical activity}

Physical activity was measured using the long form of the International Physical Activity Questionnaire (IPAQ) [35], which has been validated [36, 37]. Physical activity output was calculated as metabolic equivalents (MET) per minutes per week in the same activity domains found in the IPAQ (i.e., work-related, transportation, domestic and garden and leisure time). For each type of exercise intensity (walking, moderate, vigorous), the amount of physical activity (days week ${ }^{-1}$ ) and duration (min day ${ }^{-1}$ ) was multiplied by an appropriate MET level $\left(1 \mathrm{MET}=3.5 \mathrm{~mL} \mathrm{~kg}^{-1} \mathrm{~min}^{-1}\right)$ to determine MET $\cdot \mathrm{min}^{-1}$ week $^{-1}$ [35]. The data were analysed as a continuous variable MET $\cdot \mathrm{min}^{-1} \mathrm{week}^{-1}$ and 


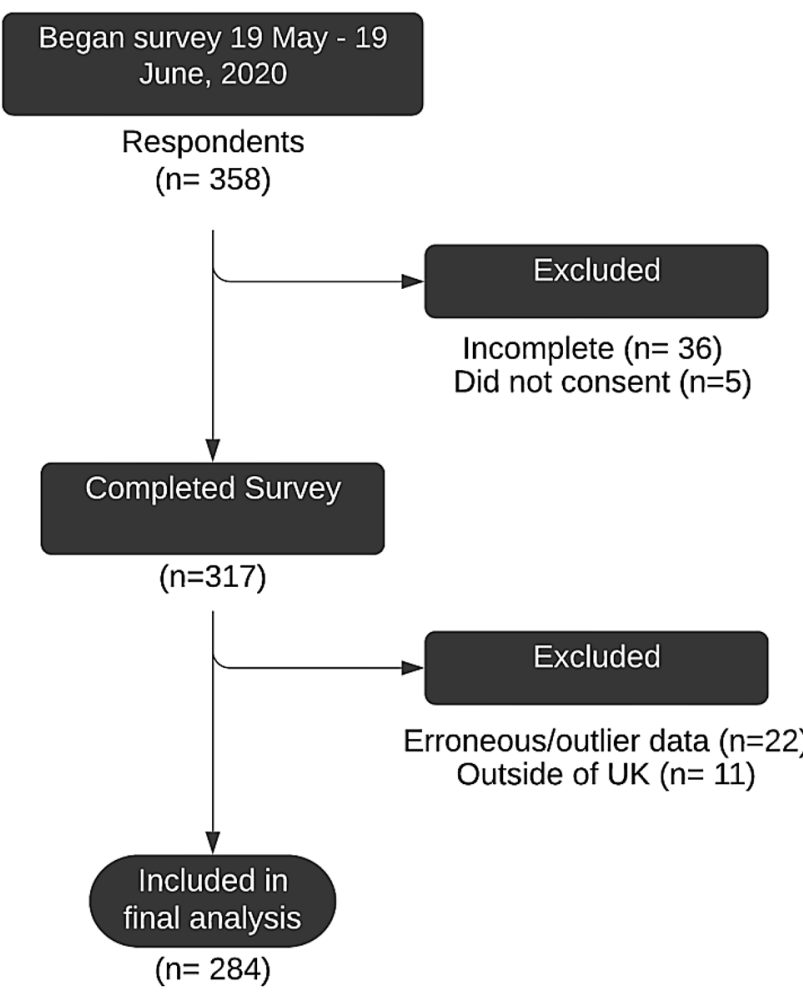

Fig. 1 CONSORT diagram of participation

as a categorical variable: (1) Meeting the physical activ-

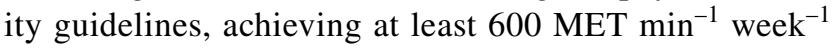
and (2) not meeting the physical activity guidelines, less than $600 \mathrm{MET} \mathrm{min}^{-1}$ week $^{-1}$. The $600 \mathrm{MET} \mathrm{min}^{-1}$ week $^{-1}$ threshold is equivalent to 150 min of moderate-intensity or $75 \mathrm{~min}$ of vigorous-intensity aerobic physical activity, throughout the week, which is the international health guidelines recommendation for physical activity [38]. We also used a pragmatic cut-point of $8 \mathrm{~h}$ a day to categorise sitting time: (1) low sitting time: $<8 \mathrm{~h} \mathrm{day}^{-1}$ and (2) high sitting time $\left(\geq 8 \mathrm{~h} \mathrm{day}^{-1}\right)$. We combined participants according to their physical activity and sedentary behaviour into four groups: (1) high sitting time ( $\left.\geq 8 \mathrm{~h} \mathrm{day}^{-1}\right)$ plus low physical activity ( $<600$ MET $\mathrm{min}^{-1}$ week $^{-1}$ ); (2) high sitting time $\left(\geq 8 \mathrm{~h} \mathrm{day}^{-1}\right)$ plus moderate or high physical activity $(\geq 600$ MET $\cdot \min ^{-1}$ week ${ }^{-1}$ ); (3) low or moderate sedentary time $\left(<8 \mathrm{~h} \mathrm{day}^{-1}\right)$ plus low physical activity group $(<600 \mathrm{MET}$ $\cdot \mathrm{min}^{-1}$ week $\left.^{-1}\right)$; and (4) low or moderate sedentary time $\left(<8 \mathrm{~h} \mathrm{day}^{-1}\right)$ plus moderate or high physical activity $(\geq 600$ MET $\min ^{-1}$ week $^{-1}$ ).

\section{Mental health}

Mental health was measured by an adapted version of the online UK Biobank mental health questionnaire. This mental health survey that has shown high face validity in relatively "healthy volunteers" [39]. The following domains of the UK Biobank questionnaire were selected to be recorded in this study: (1) screening questions; (2) current depression; (3) current anxiety disorder; and (4) wellbeing.

\section{Depression (patient health questionnaire 9-item; PHQ-9)}

The PHQ-9 contains nine items and is a well-validated measure of depression [40, 41]. Each item is scored from 0 (not at all) to 3 (almost every day), giving a range of scores from 0 to 27 , where a higher score indicates greater depression. Excellent psychometric properties have been established [40, 42]. In the current sample, Cronbach's alpha was excellent ( $\alpha=0.90$, Supplement file Table 1).

\section{Anxiety (generalized anxiety disorder scale; GAD-2)}

For the measure of anxiety, the GAD-2 was used instead of the GAD-7 as it is a brief identification tool designed to minimise completion time but still allow feasibility and accuracy of measurement in this shorter timeframe. The two items are scored from 0 (not at all) to 3 (nearly every day), providing a possible range of scores between 0 and 6 . A cut-off of 3 in the GAD-2 scale has been assessed to be the optimal sensitivity to identify GAD, and is advised as the cut-off for the NICE guidelines in anxiety disorder screening [43, 44]. Psychometric properties have been established [45], and in the present sample, Cronbach's alpha was excellent ( $\alpha=0.85$, Supplement file Table 2$)$.

\section{Subjective wellbeing}

The three wellbeing items from the UK Biobank mental health questionnaire were combined to form a total subjective wellbeing score. Each item was scored from 1 (extremely unhappy) to 6 (extremely happy) and included a response option of 0 (don't know), giving a possible range of scores between 0 and 18, with a higher score indicating greater subjective wellbeing. In the current sample, Cronbach's alpha was good ( $\alpha=0.73$, Supplement file Table 3$)$.

\section{Previous mental health difficulties}

Additionally, two dichotomous variables were created ('ever diagnosed with mood disorder' and 'ever diagnosed with anxiety disorder') by combining the relevant individual mental health problems asked in the UK Biobank questionnaire.

\section{Statistical analysis}

Data analysis was performed using IBM SPSS Statistics for Windows (Version 26.0) Descriptive analysis was used to describe the socio-demographic and health data. We used 
multivariable logistic regression to estimate the combined relationship of sitting time and physical activity adjusted for socio-demographic and health variables. We also explored the correlations between the different physical activity domains (work-related, transportation, domestic and garden and leisure time) with depression, anxiety and wellbeing total score using Spearman correlation coefficient.

Hierarchical linear regression analyses were used to explore the cumulative effects of prominent variables as specified in advance by the review in literature.

For the PHQ-9, GAD-2 and subject wellbeing regression analyses, step 1 consisted of socio-demographic and health variables (age, gender, ethnicity, employment status, income, Covid symptom presence, previous diagnosis of depression or anxiety). Step 2 consisted of weekly MET activity. Step 3 consisted of sitting time. Each step was compared to the previous step, but the coefficients of the model in the final step were interpreted further. Normality was evaluated for each model using a Q-Q scatterplot by comparing the distribution of the residuals with a normal distribution. Normality was assumed as the points formed a relatively straight line. Multicollinearity was evaluated to rule out predictor variables that may be highly correlated with one or more other predictor variables as this can affect the interpretation of the regression coefficients [46]. Variance Inflation Factors (VIF) greater than 5 are cause for concern [47], however, for all three steps in the model, all predictors have VIFs less than 10. To identify influential outliers, Studentized residuals were calculated, and the absolute values were plotted against the observation numbers. Multivariate outliers were removed before analysis using Mahalanobis distances, with the critical chi-square value at alpha 0.001 selected [48]. These were assumed to be errors outliers [49], since there was no data entry or coding errors (i.e., data were directly exported from Qualtrics XM survey to SPSS).

\section{Results}

A total of 284 participants were included in the analysis. Incomplete, invalid, and ineligible responses were not retained for analysis, representing a completion rate of $88.5 \%$ with $79.3 \%$ being analysed after exclusions.

The average age of participants was $33.5 \pm 12.4$ years. Participants' characteristics are described in Table 1. Briefly, most of the sample constituted of females, from white ethnicity, higher income (over $£ 40 \mathrm{k} \mathrm{year}^{-1}$ ), and with no preexisting health conditions.

We have also explored the effect of stage of lockdown on participants' outcome. Most participants, 78\%, took part in the study when the UK was in Phase I of the lockdown (up to $31^{\text {st }}$ of May) while $22 \%$ of the responses were collected from 1 June (Phase II). A series of t-tests revealed no significant differences in PA, siting time,
Table 1 Participants demographics consisting of gender, ethnicity, employment status, level of education, children in the house, outdoor space, and previous health condition

\begin{tabular}{|c|c|c|}
\hline Variable & $n$ & $\%$ \\
\hline \multicolumn{3}{|l|}{ Sex } \\
\hline Female & 208 & 74.8 \\
\hline Male & 68 & 24.5 \\
\hline \multicolumn{3}{|l|}{ Ethnicity } \\
\hline White & 222 & 79.9 \\
\hline Minority ethnicity & 55 & 19.8 \\
\hline \multicolumn{3}{|l|}{ Employment status } \\
\hline Student or economically inactive & 129 & 46.4 \\
\hline Employed & 147 & 52.9 \\
\hline \multicolumn{3}{|l|}{ House income } \\
\hline Over $£ 40 \mathrm{k}$ per year & 108 & 38.8 \\
\hline$£ 30-£ 40$ k per year & 47 & 16.9 \\
\hline$£ 20-£ 30$ k per year & 36 & 12.9 \\
\hline$£ 10-£ 20$ k per year & 35 & 12.6 \\
\hline Below $£ 10 \mathrm{k}$ per year & 48 & 17.3 \\
\hline \multicolumn{3}{|l|}{ Children in house } \\
\hline No children & 182 & 65.5 \\
\hline Children & 96 & 34.5 \\
\hline \multicolumn{3}{|l|}{ Outdoor space } \\
\hline Yes & 244 & 87.8 \\
\hline No & 34 & 12.2 \\
\hline \multicolumn{3}{|l|}{ Presence of health condition } \\
\hline One or more health condition & 99 & 35.6 \\
\hline No health condition & 174 & 62.6 \\
\hline \multicolumn{3}{|l|}{ COVID symptom presence } \\
\hline Yes & 46 & 16.2 \\
\hline No & 238 & 83.8 \\
\hline \multicolumn{3}{|l|}{$\begin{array}{l}\text { Previous diagnosis of mood or anxiety } \\
\text { disorder }\end{array}$} \\
\hline Mood disorder & 75 & 26.4 \\
\hline Anxiety & 77 & 27.1 \\
\hline
\end{tabular}

COVID-19 symptoms considered here are high temperature, a new continuous cough and loss or change to sense of smell or taste

depression, anxiety or wellbeing scores between the two periods of lockdown. Lockdown period was therefore not further imputed in any analysis.

Table 2 presents the combined analysis of physical activity and sitting time. Participants who reported low sitting time and low physical activity and those who reported low sitting time with moderate or high physical activity showed significantly lower depression score compared to participants with high sitting time and low physical activity (reference group). Similarly, participants with low sitting time and moderate or high physical activity had a significantly higher wellbeing score compared to those with high sitting time and low physical activity. 
Table 3 reports the association between the different domains in physical activity (i.e., work domain, transportation domain, domestic and garden domain and leisuretime) with depression, anxiety and wellbeing total score. There was a negative and significant association between depression score and domestic and garden physical activity and leisure-time physical activity domains. However, there was a significant and positive association between these same domains and wellbeing score. A similar significant positive association was noted between the work-related physical activity domain and wellbeing score.

Results from the hierarchal regression analysis was performed in three steps for each mental health outcome are detailed below.

\section{Depression}

The socio-demographic and health variables included in Step 1 analysis explained $33 \%$ of the variance of the depression score, $F(11,221)=9.70, p<0.001$. With the addition of weekly activity measured in Step 2 there was a statistically significant increase in variation of $1.5 \%$ ( $F$ change $(1,220)=5.05, p=0.026)$. Finally, in Step 3, there was a further statistically significant increase in $8 \%$ of the variance with the inclusion of sitting time ( $F$ change (1, $219)=30.89, p<0.001)$. However, weekly activity variable becomes non-significant when the sitting time was added in the model. The final model was statistically significant, $F(13,219)=12.31, p<0.001$, and explained $42 \%$ of the variance in the PHQ-9 depression scores. Younger age, female, on lower income, with one or more comorbid health conditions, previous diagnosis of mood disorder and increased sitting time independently correlated with higher depression scores (Table 4).

\section{Anxiety}

Step 1 of the analysis explained $31 \%$ of variance in the GAD-2 scores, $F(11,221)=8.95, p<0.001$. The inclusion of weekly activity did not make a statistically significant contribution to the model $(F$ change $(1,220)=0.00$, $p=0.99)$. The inclusion of sitting time at Step 3 explained an additional statistically non-significant $1 \%$ of the variance in anxiety, $F$ change $(1,219)=3.31, p=0.08$. The final model was statically significant, $F(13,219)=7.84$, $p<0.001$, and explained $32 \%$ of variance in the GAD-2 scores. Being younger, female, on lower income, having one or more comorbid health condition, and the previous diagnosis of anxiety disorder were statistically significant independent correlates of anxiety (Table 5). 
Table 3 Association between work-related, on depression, anxiety, and wellbeing scores

\begin{tabular}{lllll}
\hline & $n=269$ & Total depression Score & Total anxiety score & $\begin{array}{l}\text { Total subjective Well- } \\
\text { being score }\end{array}$ \\
\hline Work related PA & $r_{\mathrm{s}}(95 \% \mathrm{CI})$ & $-0.009(-0.21,0.03$ & $-0.04(-0.16,0.08)$ & $0.016(0.05,0.28)$ \\
& $p$ value & 0.15 & 0.553 & $0.007^{*}$ \\
Transportation PA & $r_{\mathrm{s}}(95 \% \mathrm{CI})$ & $-0.07(-0.19,-0.05)$ & $-0.02(-0.1,0.13)$ & $0.08(-0.04,0.2)$ \\
& $p$ value & 0.257 & 0.799 & 0.171 \\
Domestic and garden PA & $r_{\mathrm{s}}(95 \% \mathrm{CI})$ & $-0.13(-0.25,-0.01)$ & $-0.08(-0.2,-0.04)$ & $0.014(0.02,0.25)$ \\
& $p$ value & $0.031^{*}$ & 0.165 & $0.024^{*}$ \\
Leisure-time PA & $r_{\mathrm{s}}(95 \% \mathrm{CI})$ & $-0.16(-0.27,-0.04)$ & $-0.06(-0.18,-0.06)$ & $0.17(0.05,0.28)$ \\
& $p$ value & $0.009^{*}$ & 0.309 & $0.006^{*}$ \\
\hline
\end{tabular}

*Statistically significant

\section{Subjective wellbeing}

The sociodemographic and health variables explained $22 \%$ of the variance in the subjective wellbeing scores, $F(12$, $220)=5.03, p<0.001$. The inclusion of weekly activity at Step 2 explained an additional statistically significant $1 \%$ variance in wellbeing scores, $F$ change $(1,219)=4.60$, $p=0.03$. The inclusion of sitting time at Step 3 added an additional $4 \%$ of the variance and was statistically significant, $F$ change $(1,218)=11.67, p=0.001$. The inclusion of sitting time rendered physical activity non-significant. The final model was statistically significant, $F(14,218)=5.77$, $p<0.001$ and explained $27 \%$ of the variance in the subjective wellbeing scores. Higher wellbeing scores were independently associated with being healthy (i.e., no comorbid illness), no previous diagnosis of a mood disorder and less time sitting (Table 6).

\section{Discussion}

The primary aim of this study was to explore the effect of physical activity and sitting time on participants' mental health during the UK COVID-19 lockdown restrictions. The study found that key socio-demographic, health outcomes and sitting time explained $42 \%$ of the depression score variation, and in particular that physical activity did not account for the variation in depression score when sitting time was added in the model. The same findings were confirmed by the analysis of the combined association, which showed that those with lower sitting time had a significantly lower depression score in participants with either low or moderate/ high physical activity level. Similar results were found for wellbeing where socio-demographic, health outcomes and sitting time influenced the subjective wellbeing (27\% variance) with physical activity becoming non-significant when sitting time were taken into account. However, the combined analysis revealed that wellbeing was significantly higher in the group with low sitting time and moderate or high physical activity combined compared to the reference group (i.e., high sitting time and low physical activity). Finally, only socio-demographic and health outcomes contributed to the variation in anxiety score ( $32 \%$ variance).

The lockdown restriction has caused serious societal impacts that affected population behaviour and psychological aspects. Loneliness has increased significantly in the population, and it appeared to be maintained despite the reopening of communities [50]. Our study found that sitting time had a significant impact on depression and wellbeing. Others have highlighted the importance of reducing sedentary behaviour for mental wellbeing during COVID-19 isolation [51], which is reinforced by the literature as there is strong evidence from a meta-analysis of observational studies that sedentary behaviour is positively associated with the risk of depression [52]. However, the association between wellbeing and sedentary behaviour is controversial [53, 54], and sedentary behaviour appears to have only a small effect on anxiety $[55,56]$.

Most studies have focused on COVID-19 restrictions and the effect of physical activity on mental health [27, 27, 31], while some have highlighted the importance of sedentary behaviour [29, 58, 59]. Studies have noticed an increase in sedentary behaviour compared to pre-pandemic [29, 60], with some studies showing that prolonged sitting (more than $10 \mathrm{~h} \mathrm{day}^{-1}$ ) was associated with depressive symptoms [61]. This has similarity to our research which found that participants who sat for 8 or more hours a day had higher depression and anxiety scores and lower wellbeing, compared to participants who sat for a shorter period. In another study, sitting and screen time were also compared among participants who were considered active and inactive preCOVID-19 restrictions [29]. The research found that an increase in screen time and reduction in physical activity was associated with higher depressive symptoms and lower positive mental health in general [29]. The same findings were observed in a Brazilian population where a decrease in unhealthy movement behaviour (i.e., inactivity and 
Table 4 Hierarchical multiple regression analysis for correlates of depression scores

\begin{tabular}{|c|c|c|c|c|c|c|}
\hline & $R^{2}$ & $R^{2}$ change & $\beta$ & $B$ & SE & CI 95\% (B) \\
\hline Step 1 & $0.33 * * *$ & & & & & \\
\hline Age & & & $-0.22 * *$ & -0.12 & 0.04 & $-0.19 /-0.04$ \\
\hline Gender & & & -0.11 & -1.63 & 0.85 & $-3.31 / 0.06$ \\
\hline Ethnicity & & & $0.13 *$ & 2.17 & 0.97 & $0.26 / 4.09$ \\
\hline Employment & & & 0.00 & 0.01 & 0.94 & $-1.84 / 1.86$ \\
\hline \multicolumn{7}{|l|}{ Income $>40 \mathrm{k}$} \\
\hline$<10 \mathrm{k}$ & & & $0.18^{*}$ & 3.15 & 1.31 & $0.58 / 5.73$ \\
\hline $10-20 \mathrm{k}$ & & & 0.08 & 1.49 & 1.30 & $-1.06 / 4.04$ \\
\hline $20-30 \mathrm{k}$ & & & 0.08 & 1.55 & 1.21 & $-0.84 / 3.94$ \\
\hline $30-40 \mathrm{k}$ & & & 0.06 & 0.98 & 1.03 & $-1.05 / 3.00$ \\
\hline Comorbid health condition & & & $0.24 * * *$ & 3.10 & 0.83 & $1.47 / 4.72$ \\
\hline COVID symptoms & & & 0.08 & 1.38 & 0.97 & $-0.53 / 3.30$ \\
\hline Ever diagnosed mood disorder & & & $0.26 * * *$ & 3.59 & 0.88 & $1.86 / 5.33$ \\
\hline Step 2 & $0.34 * * *$ & 0.01 & & & & \\
\hline Age & & & $-0.21 * *$ & -0.11 & 0.04 & $-0.18 /-0.04$ \\
\hline Gender & & & -0.10 & -1.52 & 0.85 & $-3.19 / 0.15$ \\
\hline Ethnicity & & & 0.11 & 1.75 & 0.98 & $-0.18 / 3.69$ \\
\hline Employment & & & 0.02 & 0.23 & 0.94 & $-1.61 / 2.08$ \\
\hline \multicolumn{7}{|l|}{ Income $>40 \mathrm{k}$} \\
\hline$<10 \mathrm{k}$ & & & $0.18 *$ & 3.09 & 1.29 & $0.54 / 5.64$ \\
\hline $10-20 \mathrm{k}$ & & & 0.10 & 1.84 & 1.29 & $-0.71 / 4.40$ \\
\hline $20-30 \mathrm{k}$ & & & 0.08 & 1.50 & 1.20 & $-0.71 / 3.87$ \\
\hline $30-40 \mathrm{k}$ & & & 0.06 & 0.93 & 1.02 & $-1.08 / 2.93$ \\
\hline Comorbid health condition & & & $0.23 * * *$ & 2.96 & 0.82 & $1.34 / 4.57$ \\
\hline COVID symptoms & & & 0.20 & 1.76 & 0.98 & $-0.16 / 3.69$ \\
\hline Ever diagnosed mood disorder & & & $0.25 * *$ & 3.54 & 0.87 & $1.82 / 5.26$ \\
\hline Physical activity & & & $-0.13^{*}$ & -0.04 & 0.02 & $-0.08 /-0.01$ \\
\hline Step 3 & $0.42 * * *$ & 0.08 & & & & \\
\hline Age & & & $-0.18 * *$ & -0.09 & 0.03 & $-0.16 /-0.03$ \\
\hline Gender & & & $-0.13^{*}$ & -1.91 & 0.80 & $-3.48 /-0.33$ \\
\hline Ethnicity & & & -0.07 & 1.10 & 0.93 & $-0.73 / 2.93$ \\
\hline Employment & & & 0.04 & 0.51 & 0.88 & $-1.23 / 2.24$ \\
\hline \multicolumn{7}{|l|}{ Income $>40 \mathrm{k}$} \\
\hline$<10 \mathrm{k}$ & & & $0.16^{*}$ & 2.87 & 1.21 & $0.48 / 5.26$ \\
\hline $10-20 \mathrm{k}$ & & & 0.08 & 1.57 & 1.22 & $-0.83 / 3.96$ \\
\hline $20-30 \mathrm{k}$ & & & 0.08 & 1.50 & 1.13 & $-0.72 / 3.72$ \\
\hline $30-40 \mathrm{k}$ & & & 0.04 & .66 & 0.96 & $-1.22 / 2.55$ \\
\hline Comorbid health condition & & & $0.22 * * *$ & 2.82 & 0.77 & $1.30 / 4.33$ \\
\hline COVID symptoms & & & 0.06 & 1.00 & 0.93 & $-0.82 / 2.83$ \\
\hline Ever diagnosed mood disorder & & & $0.22 * *$ & 3.05 & 0.82 & $1.43 / 4.67$ \\
\hline Physical activity & & & 0.01 & 0.00 & 0.02 & $-0.04 / 0.04$ \\
\hline Sitting time & & & $0.33 * * *$ & 0.01 & 0.00 & $0.01 / 0.01$ \\
\hline
\end{tabular}

Statistical significance: $* p<0.05, * * p<0.01, * * * p<0.001$ sedentary behaviour) was associated with loneliness, sadness and anxiety during COVID-19 pandemic [62].

Although the association between sedentary behaviour and mental health during lockdown have been studied, from our knowledge, no studies have investigated the moderation effect of physical activity on the impact of sedentary behaviour on mental health outcomes. There is evidence that higher volumes of physical activity $\left(60-75 \mathrm{~min} \mathrm{day}^{-1}\right)$ are protective of the increased risk of mortality from prolonged sitting $\left(>8 \mathrm{~h} \mathrm{day}^{-1}\right)$ [63-65]. However, the mediating effect from other health outcomes and in particular mental health is less clear [66, 67]. Using 
Table 5 Hierarchical multiple regression analysis results for correlates of anxiety scores

\begin{tabular}{|c|c|c|c|c|c|c|}
\hline & $R^{2}$ & $R^{2}$ change & $\beta$ & $B$ & SE & CI 95\% (B) \\
\hline Step 1 & $0.31 * * *$ & & & & & \\
\hline Age & & & $-0.19 * *$ & -0.03 & 0.01 & $-0.05 /-0.01$ \\
\hline Gender & & & $-0.24 * * *$ & -1.07 & 0.26 & $-1.59 /-0.56$ \\
\hline Ethnicity & & & -0.02 & -0.12 & 0.29 & $-0.70 / 0.46$ \\
\hline Employment & & & 0.03 & 0.12 & 0.29 & $-0.45 / 0.68$ \\
\hline \multicolumn{7}{|l|}{ Income $>40 \mathrm{k}$} \\
\hline$<10 \mathrm{k}$ & & & $0.15^{*}$ & 0.80 & 0.39 & $0.03 / 1.58$ \\
\hline $10-20 \mathrm{k}$ & & & 0.10 & 0.59 & 0.39 & $-0.18 / 1.36$ \\
\hline $20-30 \mathrm{k}$ & & & 0.05 & 0.30 & 0.37 & $-0.43 / 1.02$ \\
\hline $30-40 \mathrm{k}$ & & & 0.07 & 0.37 & 0.31 & $-0.25 / 0.98$ \\
\hline Comorbid health condition & & & $0.16^{* *}$ & 0.63 & 0.23 & $0.17 / 1.09$ \\
\hline COVID symptoms & & & -0.01 & -0.03 & 0.30 & $-0.61 / 0.55$ \\
\hline Ever diagnosed anxiety disorder & & & $0.26 * * *$ & 1.10 & 0.25 & $0.61 / 1.59$ \\
\hline Step 2 & $0.31 * * *$ & 0.00 & & & & \\
\hline Age & & & $-0.19 * *$ & -0.03 & 0.01 & $-0.05 / 0.01$ \\
\hline Gender & & & $-0.24 * * *$ & -1.07 & 0.26 & $-1.59 /-0.56$ \\
\hline Ethnicity & & & -0.02 & -0.12 & 0.30 & $-0.71 / 0.48$ \\
\hline Employment & & & 0.03 & .12 & 0.29 & $-0.45 / 0.68$ \\
\hline \multicolumn{7}{|l|}{ Income $>40 \mathrm{k}$} \\
\hline$<10 \mathrm{k}$ & & & $0.15^{*}$ & 0.80 & 0.39 & $0.03 / 1.58$ \\
\hline $10-20 \mathrm{k}$ & & & 0.10 & 0.59 & 0.40 & $-0.19 / 1.37$ \\
\hline $20-30 \mathrm{k}$ & & & 0.05 & 0.30 & 0.37 & $-0.43 / 1.02$ \\
\hline $30-40 \mathrm{k}$ & & & 0.07 & 0.37 & 0.31 & $-0.24 /-0.25$ \\
\hline Comorbid health condition & & & $0.16^{* * *}$ & 0.63 & 0.24 & $0.16 / 1.09$ \\
\hline COVID symptoms & & & -0.01 & -0.03 & 0.30 & $-0.62 / 0.56$ \\
\hline Ever diagnosed anxiety disorder & & & $0.26 * * *$ & 1.10 & 0.25 & $0.60 / 1.59$ \\
\hline Physical activity & & & 0.00 & -02.56 & 0.01 & $-0.01 / .01$ \\
\hline Step 3 & $0.32 * * *$ & 0.01 & & & & \\
\hline Age & & & $-0.18^{*}$ & -0.03 & 0.01 & $-0.05 /-0.01$ \\
\hline Gender & & & $-025 * * *$ & -1.12 & 0.26 & $-1.63 /-0.60$ \\
\hline Ethnicity & & & -.04 & -0.18 & 0.30 & $-0.77 / 0.41$ \\
\hline Employment & & & 0.04 & 0.14 & 0.29 & $-0.43 / 0.71$ \\
\hline \multicolumn{7}{|l|}{ Income $>40 \mathrm{k}$} \\
\hline$<10 \mathrm{k}$ & & & $0.15 *$ & 0.77 & 0.39 & $-0.00 / 1.55$ \\
\hline $10-20 \mathrm{k}$ & & & 0.10 & 0.77 & 0.39 & $-0.22 / 1.34$ \\
\hline $20-30 \mathrm{k}$ & & & 0.05 & 0.30 & 0.37 & $-0.43 / 1.02$ \\
\hline $30-40 \mathrm{k}$ & & & 0.07 & 0.34 & 0.31 & $-0.28 / .95$ \\
\hline Comorbid health condition & & & $0.15^{*}$ & 0.60 & 0.23 & $0.14 / 1.06$ \\
\hline COVID symptoms & & & -.02 & -.10 & .30 & $-0.70 / 0.49$ \\
\hline Ever diagnosed anxiety disorder & & & $0.25 * *$ & 1.05 & .25 & $0.56 / 1.55$ \\
\hline Physical activity & & & 0.05 & .01 & .01 & $0.02 /-0.03$ \\
\hline Sitting time & & & 0.11 & .00 & .00 & $0.00 / 0.14$ \\
\hline
\end{tabular}

Statistical significance: $* p<0.05, * * p<0.01, * * * p<0.001$ compositional analysis of associations [68], a study found that self-reported mental health measured by a single mental health question, was significantly associated with physical activity in older adults (65-79 years). However, sedentary behaviour did not impact on mental health in young (18-64 years) or older age group (65-79 years)
[69]. This is in contradiction to the findings of our study, with a younger population ( $33.5 \pm 12.4$ years), which used a more comprehensive assessment of mental health (UK Biobank mental health assessment). However, physical activity and sitting time were self-reported in our study, rather than objectively measured compared with previous 
Table 6 Hierarchical multiple regression analysis for correlates of wellbeing scores

\begin{tabular}{|c|c|c|c|c|c|c|}
\hline & $R^{2}$ & $R^{2}$ change & $\beta$ & $B$ & SE & CI 95\% (B) \\
\hline Step 1 & $0.22 * * *$ & & & & & \\
\hline Age & & & 0.12 & 0.03 & 0.02 & $-0.01 / 0.06$ \\
\hline Gender & & & -0.01 & -0.08 & 0.37 & $-0.82 / 0.65$ \\
\hline Ethnicity & & & 0.02 & 0.13 & 0.42 & $-0.71 / 0.96$ \\
\hline Employment & & & -0.02 & -0.08 & 0.41 & $-.89 / 0.73$ \\
\hline \multicolumn{7}{|l|}{ Income $>40 \mathrm{k}$} \\
\hline$<10 \mathrm{k}$ & & & -0.16 & --1.10 & .57 & $-2.22 / 0.01$ \\
\hline $10-20 \mathrm{k}$ & & & -0.01 & -0.04 & 0.56 & $1.15 / 1.07$ \\
\hline $20-30 \mathrm{k}$ & & & -0.02 & -0.12 & 0.53 & $-1.15 / 0.92$ \\
\hline $30-40 \mathrm{k}$ & & & -0.06 & -0.40 & 0.45 & $-1.28 / 0.48$ \\
\hline Comorbid health condition & & & $-0.25 * * *$ & -1.30 & 0.36 & $-2.01 / 0.59$ \\
\hline COVID symptoms & & & 0.01 & 0.05 & 0.42 & $-0.78 / 0.89$ \\
\hline Ever diagnosed mood disorder & & & $-0.26 * * *$ & -1.47 & 0.48 & $-2.27 /-0.66$ \\
\hline Ever diagnosed anxiety disorder & & & .07 & 0.37 & 0.38 & $-0.39 / 1.12$ \\
\hline Step 2 & $0.23 * * *$ & 0.01 & & & & \\
\hline Age & & & 0.11 & 0.02 & 0.02 & $-0.01 / .05$ \\
\hline Gender & & & -0.02 & -0.13 & 0.37 & $-0.87 / .60$ \\
\hline Ethnicity & & & 0.05 & 0 & 0.43 & $-0.54 / 1.14$ \\
\hline Employment & & & -0.04 & -0.18 & 0.41 & $-0.99 / .63$ \\
\hline \multicolumn{7}{|l|}{ Income $>40 \mathrm{k}$} \\
\hline$<10 \mathrm{k}$ & & & -0.15 & -1.08 & 0.56 & $-2.19 / .03$ \\
\hline $10-20 \mathrm{k}$ & & & -0.02 & -.19 & 0.56 & $-1.30 / .93$ \\
\hline $20-30 \mathrm{k}$ & & & -0.01 & -.09 & 0.52 & $-1.13 / .94$ \\
\hline $30-40 \mathrm{k}$ & & & -0.06 & -.38 & 0.44 & $-1.25 / .49$ \\
\hline Comorbid health condition & & & $-0.24 * * *$ & -1.24 & 0.36 & $-1.62 /-0.53$ \\
\hline COVID symptoms & & & -0.01 & -0.10 & 0.43 & $-0.94 / 0.74$ \\
\hline Ever diagnosed mood disorder & & & $-0.25^{* * *}$ & -1.43 & 0.41 & $-2.23 / 0.63$ \\
\hline Ever diagnosed anxiety disorder & & & 0.06 & 0.34 & 0.38 & $-0.41 / 1.09$ \\
\hline Physical activity & & & $0.13^{*}$ & 0.02 & 0.01 & $0.00 / 0.04$ \\
\hline Step 3 & $0.27 * * *$ & 0.04 & & & & \\
\hline Age & & & 0.09 & 0.02 & 0.02 & $-0.01 / .05$ \\
\hline Gender & & & -0.00 & -0.02 & 0.37 & $-0.73 / .70$ \\
\hline Ethnicity & & & 0.07 & 0.49 & 0.42 & $-0.34 / 1.31$ \\
\hline Employment & & & -0.05 & -0.24 & 0.40 & $-1.03 / 0.55$ \\
\hline \multicolumn{7}{|l|}{ Income $>40 \mathrm{k}$} \\
\hline$<10 \mathrm{k}$ & & & -0.14 & -1.01 & 0.55 & $-2.10 / 0.07$ \\
\hline $10-20 \mathrm{k}$ & & & -0.02 & -0.11 & 0.55 & $-1.20 / 0.97$ \\
\hline $20-30 \mathrm{k}$ & & & -0.01 & -0.10 & 0.51 & $-1.10 / 0.91$ \\
\hline $30-40 \mathrm{k}$ & & & -0.05 & -0.30 & 0.43 & $-1.16 / 0.55$ \\
\hline Comorbid health condition & & & $-2.30 * * *$ & -1.21 & 0.35 & $-1.90 /-0.52$ \\
\hline COVID symptoms & & & 0.02 & 0.10 & 0.42 & $-0.73 / 0.93$ \\
\hline Ever diagnosed mood disorder & & & $-0.24 * * *$ & -1.33 & 0.40 & $-2.11 /-0.55$ \\
\hline Ever diagnosed anxiety disorder & & & 0.08 & 0.43 & 0.37 & $-0.30 / 1.17$ \\
\hline Physical activity & & & 0.04 & 0.01 & 0.01 & $-0.01 / 0.02$ \\
\hline Sitting time & & & $-0.23 * * *$ & -0.00 & 0.00 & $-0.00 /-0.00$ \\
\hline
\end{tabular}

Statistical significance: $* p<0.05, * * p<0.01, * * * p<0.001$ study [68]. The type of measurement might have affected the association outcome. The analysis of data from the Health Survey for England revealed that only objectively measured light-intensity activity was associated with a lower risk of psychological distress rather than selfreported data. However, sedentary time was associated with adverse mental health, independently if measured objectively or self-reported [70]. 
This study found only a minimum effect of physical activity on depression score, which turned out to be non-significant when sitting time was imputed into the model. This was further supported by the combined analysis of the effect of sitting time and physical activity (Table 2). The sub analysis which examined the relationship between different domains of physical activity and mental health outcomes revealed that domestic and garden physical activity and leisure-time physical activity domains were negatively associated with depression and positively associated with wellbeing. Similarly, the work-related domain was positively correlated with wellbeing. However, these results need to be interpreted with caution as the overall effect of physical measured by the mixed model was not significant and small sample size, increasing the possibility of a Type I error.

A study with a large cohort of Australian women, also found that domestic and garden work were positively correlated with physical and mental wellbeing in mid-aged (50-55 years) and older women ( $76-81$ years) but negatively associated with younger women (25-30 years) [71].Our study consisted primarily of women $(74.8 \%)$ at a younger age (33.5 \pm 12.4 years). However, our study was conducted during lockdown restrictions in which the opportunities to do physical activity were very restricted. Gardening, in particular, showed a positive impact on psychopathological distress, in a study conducted in Italy, during the Covid-19 lockdown [72]. Concerning leisure-time there is strong evidence from a meta-analysis that leisure-time physical activity positively affects mental health [73]. However, the same study showed ambiguous results concerning work-related physical activity as a significant positive association was observed with mental health but also with mental ill-health, which the authors justify as variation in the population between the different studies. In our study, the opportunity to go out to work and do a labour job which requires moderate or vigorous levels of physical activity, during lockdown, might have had positive impact of participants wellbeing giving a sensation of freedom and normality, but again caution in interpretation of these findings are needed.

Finally, all model analysis has shown an association between particular socio-demographic outcomes and preexisting conditions on mental health domains. Common socio-demographic predictors for depression and anxiety were young and female. The main course of recruitment in this study were university students. It is known that university students have higher rates of depression compared to the general population [74]. It is also known that women are twice more likely than men to suffer from depression, with the increased risk persisting until the mid-50 s [75]. Likewise, anxiety disorders are more prevalent and disabling in women compared to men [76]. Other factors that were associated with mental health problems in this study were lower-income, with one or more comorbid health conditions or previous diagnosis of mental health disorder. This is echoed by other studies which explored the predisposing factors of mental health problems during COVID-19 pandemic [77].

This study has a few limitations, including the cross-sectional design which precludes us from making inferences on causality. Likewise, the use of self-reported physical activity has low validity compared to objective measures of physical activity and sedentary (i.e., accelerometers) [78]. However, the use of objective measures is not viable, especially in lockdown circumstances. Some considerations need to be taken when interpreting the findings of this study. The sample consisted primarily of healthy and active individuals as $78 \%$ of our sample meet the recommendations for physical activity. However, $55 \%$ of our sample reported a sitting time of more than $8 \mathrm{~h}$ a day. This sufficiently active but sedentary at the same time might have skewed our findings compared to studies which recruited a primarily inactive population during COVID-19 lockdown restrictions. Likewise, although we performed further analysis to explore the association of different physical activity domains with mental health outcomes, the same analysis could not be performed for sedentary behaviour since the IPAQ questionnaire does not contain questions on domains of sedentary behaviour. There is evidence suggesting that type sedentary behaviour might have a different impact on mental health, with TV viewing, for example, having a negative effect while reading and working showing no association or a positive effect $[79,80]$. Future studies should investigate the impact of different sedentary behaviour activities on mental health outcomes. Likewise, our sample constituted primarily of females (74.8\%), limiting our ability to generalise the findings to a mixedgender population. The reason for more females in our sample is perhaps because women are more likely than men to respond to research surveys [81]. Also, our recruitment focused primarily on University staff and students from the School of Health, who are predominately female. However, the study has some strengths, including the use of a comprehensive assessment of mental health and a robust statistical analysis with adjustment of socio-demographic and health cofounders.

\section{Conclusion}

During strict lockdown in the UK, the government underlined the importance of being physically active by allowing people to exercise as one of the only reasons they could leave their homes. This policy recommendation is welcome, considering the plethora of benefits of physical activity on health and wellbeing. However, the findings from this study and others from the literature, have revealed that reducing sedentary behaviour or sitting time might have a positive effect on individuals mental health, suggesting that public health recommendations should encourage the reduction 
of sitting time for mental health benefits. The advocate of reducing sitting time might be easier to implement in individuals or populations with mobility impairment or functional disability.

Author contributions MP: data analysis, writing, reviewing and editing; SK-P: conceptualization, methodology, data analysis, writing, reviewing and editing; LA: conceptualization, methodology, data analysis, writing reviewing and editing.

Funding The Strategic Research Investment Fund rapid response COVID-19-related research and seed funding, University of Huddersfield.

\section{Declarations}

Conflict of interest The authors have no conflict of interests to report.

Ethical approval The study received ethical approval from the School of Human \& Health Sciences at the University of Huddersfield (application number SREIC/2020/051).

Informed consent Participants were informed at the beginning of the survey that participation was voluntary and provided with further information about the study. Informed consent was implied by completing the questionnaire.

Open Access This article is licensed under a Creative Commons Attribution 4.0 International License, which permits use, sharing, adaptation, distribution and reproduction in any medium or format, as long as you give appropriate credit to the original author(s) and the source, provide a link to the Creative Commons licence, and indicate if changes were made. The images or other third party material in this article are included in the article's Creative Commons licence, unless indicated otherwise in a credit line to the material. If material is not included in the article's Creative Commons licence and your intended use is not permitted by statutory regulation or exceeds the permitted use, you will need to obtain permission directly from the copyright holder. To view a copy of this licence, visit http://creativecommons.org/licenses/by/4.0/.

\section{References}

1. Rothan HA, Byrareddy SN (2020) The epidemiology and pathogenesis of coronavirus disease (COVID-19) outbreak. J Autoimmun 109:102433

2. Public Health England (2020) [Withdrawn] Guidance on social distancing for everyone in the UK. https://www.gov.uk/gover nment/publications/covid-19-guidance-on-social-distancing-andfor-vulnerable-people/guidance-on-social-distancing-for-every one-in-the-uk-and-protecting-older-people-and-vulnerable-adults. Accessed 4 Aug 2020

3. Qiu J, Shen B, Zhao M, Wang Z, Xie B, Xu Y (2020) A nationwide survey of psychological distress among Chinese people in the COVID-19 epidemic: implications and policy recommendations. Gen Psychiatry. https://doi.org/10.1136/gpsych-2020-100213

4. Liu S, Yang L, Zhang C et al (2020) Online mental health services in China during the COVID-19 outbreak. Lancet Psychiatry 7(4):e17-e18. https://doi.org/10.1016/S2215-0366(20)30077-8
5. Wang C, Pan R, Wan X et al (2020) Immediate psychological responses and associated factors during the initial stage of the 2019 coronavirus disease (COVID-19) epidemic among the general population in China. Int $J$ Environ Res Public Health 17(5):1729. https://doi.org/10.3390/ijerph17051729

6. Altena E, Baglioni C, Espie CA, Ellis J, Gavriloff D, Holzinger B, Schlarb A, Frase L, Jernelöv S, Riemann D (2020) Dealing with sleep problems during home confinement due to the COVID19 outbreak: Practical recommendations from a task force of the European CBT-I Academy. J Sleep Res 29(4):e13052. https://doi. org/10.1111/jsr.13052

7. Clay JM, Parker MO (2020) Alcohol use and misuse during the COVID-19 pandemic: a potential public health crisis? Lancet Public Health 5(5):e259. https://doi.org/10.1016/S2468-2667(20) 30088-8

8. World Health Organisation (2020) Depression. https://www.who. int/news-room/fact-sheets/detail/depression . Accessed 8 Oct 2020

9. Bandelow B, Michaelis S (2015) Epidemiology of anxiety disorders in the 21st century. Dialogues Clin Neurosci 17(3):327

10. Mushtaq R, Shoib S, Shah T, Mushtaq S (2014) Relationship between loneliness, psychiatric disorders and physical health? A review on the psychological aspects of loneliness. JCDR 8(9):WE01

11. Beutel ME, Klein EM, Brähler E et al (2017) Loneliness in the general population: prevalence, determinants and relations to mental health. BMC Psychiatry 17(1):1-7

12. Valtorta NK, Kanaan M, Gilbody S, Ronzi S, Hanratty B (2016) Loneliness and social isolation as risk factors for coronary heart disease and stroke: systematic review and meta-analysis of longitudinal observational studies. Heart 102(13):1009-1016

13. Elovainio M, Hakulinen C, Pulkki-Råback L et al (2017) Contribution of risk factors to excess mortality in isolated and lonely individuals: an analysis of data from the UK Biobank cohort study. Lancet Public Health 2(6):e260-e266

14. Leigh-Hunt N, Bagguley D, Bash K et al (2017) An overview of systematic reviews on the public health consequences of social isolation and loneliness. Public Health 152:157-171

15. Kiecolt-Glaser JK, Glaser R (2002) Depression and immune function: central pathways to morbidity and mortality. J Psychosom Res 53(4):873-876

16. Hawkley LC, Cacioppo JT (2010) Loneliness matters: a theoretical and empirical review of consequences and mechanisms. Ann Behav Med 40(2):218-227

17. Qin C, Zhou L, Hu Z et al (2020) Dysregulation of immune response in patients with COVID-19 in Wuhan, China. Clin Infect Dis 71:762-728

18. Nguyen HC, Nguyen MH, Do BN et al (2020) People with suspected COVID-19 symptoms were more likely depressed and had lower health-related quality of life: the potential benefit of health literacy. J Clin Med 9(4):965

19. Pelletier L, Shamila S, Patten Scott B, Demers A (2017) Selfmanagement of mood and/or anxiety disorders through physical activity/exercise. Health Promot Chronic Dis Prev Can 37(5):27

20. Kandola A, Vancampfort D, Herring M et al (2018) Moving to beat anxiety: epidemiology and therapeutic issues with physical activity for anxiety. Curr Psychiatry Rep 20(8):63

21. Parker AG, Hetrick SE, Jorm AF et al (2016) The effectiveness of simple psychological and physical activity interventions for high prevalence mental health problems in young people: a factorial randomised controlled trial. J Affect Disord 196:200-209

22. Mammen G, Faulkner G (2013) Physical activity and the prevention of depression: a systematic review of prospective studies. Am J Prev Med 45(5):649-657. https://doi.org/10.1016/j. amepre.2013.08.001

23. Rosenbaum S, Tiedemann A, Sherrington C, Curtis J, Ward PB (2014) Physical activity interventions for people with mental 
illness: a systematic review and meta-analysis. J Clin Psychiatry 75(9):964-974

24. BBC news (2020) Coronavirus: Strict new curbs on life in UK announced by PM. https://www.bbc.co.uk/news/uk-52012432. Accessed 24 Oct 2020

25. Government Digital Service GOV. UK (2020) Staying at home and away from others (social distancing). https://www.gov.uk/ government/publications/full-guidance-on-staying-at-homeand-away-from-others/full-guidance-on-staying-at-home-andaway-from-others. Accessed 9 Oct 2020

26. Ammar A, Brach M, Trabelsi K et al (2020) Effects of COVID19 home confinement on eating behaviour and physical activity: results of the ECLB-COVID19 international online survey. Nutrients 12(6):1583

27. Lesser IA, Nienhuis CP (2020) The impact of COVID-19 on physical activity behavior and well-being of Canadians. Int $\mathrm{J}$ Environ Res Public Health 17(11):3899

28. Stanton R, To QG, Khalesi S et al (2020) Depression, anxiety and stress during COVID-19: associations with changes in physical activity, sleep, tobacco and alcohol use in Australian adults. Int J Environ Res Public Health 17(11):4065

29. Meyer J, McDowell C, Lansing J et al (2020) Changes in physical activity and sedentary behavior in response to COVID-19 and their associations with mental health in 3,052 US adults. Int J Environ Res Public Health 17:6469

30. Callow DD, Arnold-Nedimala NA, Jordan LS et al (2020) The mental health benefits of physical activity in older adults survive the COVID-19 pandemic. Am J Geriatr Psych 28:1046-1057

31. Jacob L, Tully MA, Barnett Y et al (2020) The relationship between physical activity and mental health in a sample of the UK public: a cross-sectional study during the implementation of COVID-19 social distancing measures. Ment Health Phys Activity 19:100345

32. Edwards MK, Loprinzi PD (2016) Effects of a sedentary behaviorinducing randomized controlled intervention on depression and mood profile in active young adults, vol 91. Elsevier, Amsterdam, pp 984-998

33. von Elm E, Altman DG, Egger M, Pocock SJ, Gøtzsche PC, Vandenbroucke JP (2008) The strengthening the reporting of observational studies in epidemiology (STROBE) statement: guidelines for reporting observational studies. J Clin Epidemiol 61(4):344 349. https://doi.org/10.1016/j.jclinepi.2007.11.008

34. Qualtrics (2020) Leading experience management \& survey software. https://www.qualtrics.com/uk/. Accessed 5 Aug 2020

35. International physical activity questionnaire (2020) IPAQ Scoring Protocol. https://sites.google.com/site/theipaq/scoring-protocol. Accessed 8 Oct 2020

36. Craig CL, Marshall AL, Sjöström M et al (2003) International physical activity questionnaire: 12-country reliability and validity. Med Sci Sports Exerc 35(8):1381-1395

37. Helmerhorst HHJ, Brage S, Warren J, Besson H, Ekelund U (2012) A systematic review of reliability and objective criterionrelated validity of physical activity questionnaires. Int $\mathbf{J}$ Behav Nutr Phys Act 9(1):103

38. National Health Service (2018) Exercise. https://www.nhs.uk/livewell/exercise/. Accessed 9 Oct 2020

39. Davis KA, Coleman JR, Adams M et al (2020) Mental health in UK Biobank-development, implementation and results from an online questionnaire completed by 157366 participants: a reanalysis. BJPsych Open 6(2):e18

40. Cameron IM, Crawford JR, Lawton K, Reid IC (2008) Psychometric comparison of PHQ-9 and HADS for measuring depression severity in primary care. Br J Gen Pract 58(546):32-36

41. Kroenke K, Spitzer RL, Williams JBW (2001) The PHQ-9. J Gen Intern Med 16(9):606-613. https://doi.org/10.1046/j.1525-1497. 2001.016009606.x
42. Kim YE, Lee B (2019) The psychometric properties of the patient health questionnaire-9 in a sample of Korean University students. Psychiatry Investig 16(12):904-910. https://doi.org/10.30773/pi. 2019.0226

43. Plummer F, Manea L, Trepel D, McMillan D (2016) Screening for anxiety disorders with the GAD-7 and GAD-2: a systematic review and diagnostic metaanalysis. Gen Hosp Psychiatry 39:24 31. https://doi.org/10.1016/j.genhosppsych.2015.11.005

44. National Collaborating Centre for Mental Health (UK) (2011) Common mental health disorders: identification and pathways to care. British Psychological Society, Leicester

45. Kroenke K, Spitzer RL, Williams JB, Monahan PO, Löwe B (2007) Anxiety disorders in primary care: prevalence, impairment, comorbidity, and detection. Ann Intern Med 146(5):317-325

46. Yoo W, Mayberry R, Bae S, Singh K, Peter He Q, Lillard JW (2014) A study of effects of multicollinearity in the multivariable analysis. Int J Appl Sci Technol 4(5):9-19

47. O'brien RM (2007) A caution regarding rules of thumb for variance inflation factors. Qual Quant 41(5):673-690. https://doi.org/ 10.1007/s11135-006-9018-6

48. Tabachnick BG, Fidell LS, Ullman JB (2007) Using multivariate statistics, vol 5. Pearson, Boston

49. Aguinis H, Gottfredson RK, Joo H (2013) Best-practice recommendations for defining, identifying, and handling outliers. Organ Res Methods 16(2):270-301

50. Killgore WD, Cloonan SA, Taylor EC, Miller MA, Dailey NS (2020) Three months of loneliness during the COVID-19 lockdown. Psychiatry Res 293:113392

51. Diamond R, Byrd E (2020) Standing up for health-improving mental wellbeing during COVID-19 isolation by reducing sedentary behaviour. J Affect Disord 277:232-234

52. Zhai L, Zhang Y, Zhang D (2015) Sedentary behaviour and the risk of depression: a meta-analysis. Br J Sports Med 49(11):705-709

53. Okely JA, Čukić I, Shaw RJ et al (2019) Positive and negative well-being and objectively measured sedentary behaviour in older adults: evidence from three cohorts. BMC Geriatr 19(1):28

54. Atkin AJ, Adams E, Bull FC, Biddle SJ (2012) Non-occupational sitting and mental well-being in employed adults. Ann Behav Med 43(2):181-188

55. Teychenne M, Costigan SA, Parker K (2015) The association between sedentary behaviour and risk of anxiety: a systematic review. BMC Public Health 15(1):1-8

56. Allen MS, Walter EE, Swann C (2019) Sedentary behaviour and risk of anxiety: a systematic review and meta-analysis. J Affect Disord 242:5-13

57. Faulkner J, O'Brien W, McGrane B et al (2020) Physical activity, mental health and well-being of adults during early COVID-19 containment strategies: a multi-country cross-sectional analysis. medRxiv 24:320-326

58. Asiamah N, Opuni FF, Mends-Brew E, Mensah SW, Mensah HK, Quansah F (2020) Short-term changes in behaviors resulting from COVID-19-related social isolation and their influences on mental health. Community Ment Health 57:79-92

59. Martinez EZ, Silva FM, Morigi TZ et al (2020) Physical activity in periods of social distancing due to COVID-19: a cross-sectional survey. Cien Saude Colet 25:4157-4168

60. Zheng C, Huang WY, Sheridan S, Sit CH-P, Chen X-K, Wong SH-S (2020) COVID-19 pandemic brings a sedentary lifestyle in young adults: a cross-sectional and longitudinal study. Int $\mathbf{J}$ Environ Res Public Health 17(17):6035

61. Schuch FB, Bulzing RA, Meyer J et al (2020) Associations of moderate to vigorous physical activity and sedentary behavior with depressive and anxiety symptoms in self-isolating people during the COVID-19 pandemic: a cross-sectional survey in Brazil. Psychiatry Res 292:113339 
62. Werneck AO, Silva DR, Malta DC et al (2020) Changes in the clustering of unhealthy movement behaviors during the COVID19 quarantine and the association with mental health indicators among Brazilian adults. Transl Behav Med 11:323-331

63. Ekelund U, Steene-Johannessen J, Brown WJ et al (2016) Does physical activity attenuate, or even eliminate, the detrimental association of sitting time with mortality? A harmonised metaanalysis of data from more than 1 million men and women. Lancet 388(10051):1302-1310

64. Ekelund U, Tarp J, Steene-Johannessen J et al (2019) Doseresponse associations between accelerometry measured physical activity and sedentary time and all cause mortality: systematic review and harmonised meta-analysis. BMJ 366:14570

65. Wijndaele K, Duvigneaud N, Matton L et al (2009) Sedentary behaviour, physical activity and a continuous metabolic syndrome risk score in adults. Eur J Clin Nutr 63(3):421-429

66. Biswas A, Oh PI, Faulkner GE et al (2015) Sedentary time and its association with risk for disease incidence, mortality, and hospitalization in adults: a systematic review and meta-analysis. Ann Intern Med 162(2):123-132

67. Janssen I, Clarke AE, Carson V et al (2020) A systematic review of compositional data analysis studies examining associations between sleep, sedentary behaviour, and physical activity with health outcomes in adults. Appl Physiol Nutr Metab 45(10):S248-S257

68. Chastin SF, Palarea-Albaladejo J, Dontje ML, Skelton DA (2015) Combined effects of time spent in physical activity, sedentary behaviors and sleep on obesity and cardio-metabolic health markers: a novel compositional data analysis approach. PLoS ONE 10(10): 0139984

69. McGregor DE, Carson V, Palarea-Albaladejo J, Dall PM, Tremblay MS, Chastin SF (2018) Compositional analysis of the associations between 24-h movement behaviours and health indicators among adults and older adults from the canadian health measure survey. Int J Environ Res Public Health 15(8):1779

70. Hamer M, Coombs N, Stamatakis E (2014) Associations between objectively assessed and self-reported sedentary time with mental health in adults: an analysis of data from the Health Survey for England. BMJ Open 46:718-723

71. Peeters G, van Gellecum YR, van Uffelen JG, Burton NW, Brown WJ (2014) Contribution of house and garden work to the association between physical activity and well-being in young, mid-aged and older women. Br J Sports Med 48(12):996-1001
72. Theodorou A, Panno A, Carrus G, Carbone GA, Massullo C, Imperatori $C$ (2021) Stay home, stay safe, stay green: The role of gardening activities on mental health during the Covid-19 home confinement. Urban For Urban Green 61:127091

73. White RL, Babic MJ, Parker PD, Lubans DR, Astell-Burt T, Lonsdale C (2017) Domain-specific physical activity and mental health: a meta analysis. Am J Prev Med 52(5):653-666

74. Ibrahim AK, Kelly SJ, Adams CE, Glazebrook C (2013) A systematic review of studies of depression prevalence in university students. J Psychiatr Res 47(3):391-400

75. Sassarini J (2016) Depression in midlife women. Maturitas 94:149-154

76. McLean CP, Asnaani A, Litz BT, Hofmann SG (2011) Gender differences in anxiety disorders: prevalence, course of illness, comorbidity and burden of illness. J Psychiatr Res 45(8):1027-1035

77. González-Sanguino C, Ausín B, ÁngelCastellanos M et al (2020) Mental health consequences during the initial stage of the 2020 coronavirus pandemic (COVID-19) in Spain. Brain Behav Immun $87: 172-176$

78. Dyrstad SM, Hansen BH, Holme IM, Anderssen SA (2014) Comparison of self-reported versus accelerometer-measured physical activity. Med Sci Sports Exerc 46(1):99-106

79. Hallgren M, Owen N, Stubbs B, Zeebari Z, Vancampfort D, Schuch F, Bellocco R, Dunstan D, Trolle Lagerros Y (2018) Passive and mentally-active sedentary behaviors and incident major depressive disorder: a 13-year cohort study. J Affect Disord 241:579-585

80. Werneck AO, Hoare E, Stubbs B, van Sluijs EMF, Corder K (2021) Associations between mentally-passive and mentallyactive sedentary behaviours during adolescence and psychological distress during adulthood. Prev Med 145:106436

81. Curtin R, Presser S, Singer E (2000) The effects of response rate changes on the index of consumer sentiment. Public Opin Q 64(4):413-428

Publisher's Note Springer Nature remains neutral with regard to jurisdictional claims in published maps and institutional affiliations. 